\title{
Desenvolvendo o pensamento crítico através da EAD
}

\author{
Leonardo Sartori Porto, UFRGS \\ leonardo.porto@ufrgs.br
}

Resumo: O artigo aborda a utilização da educação a distancia através da internet para o desenvolvimento do pensamento crítico. O artigo analisa a experiência do desenvolvimento de competências de argumentação através do ensino da disciplina de "Filosofia da Educação" e da disciplina de "Seminário Integrador".

Palavras-chave: pensamento crítico, argumentação, Filosofia da Educação, educação a distância

\section{Developing critical thinking through Distance Learning}

Abstract: The article discusses the use of distance education via the Internet to the development of critical thinking. The article analyzes the experience to develop skills of argument by teaching the discipline of "Philosophy of Education" and the discipline of "Seminário Integrador".

Keywords: critical thinking, argumentation, Philosophy of Education, Distance Learning. 
No livro "Os Robôs", Isaac Asimov descreve um planeta sem cidades, apenas com vastas fazendas, o que somado a uma tecnologia de comunicação bastante avançada, gerou uma sociedade onde as pessoas têm aversão ao contato físico. A imaginação de Asimov descreve um dos temores associados ao EAD: o rompimento dos vínculos sócio-afetivos entre professores e alunos.

Com relação ao ensino acadêmico cabe notar que lidamos com alunos adultos, e que, portanto, já possuem condições sócio-afetivas para realizar uma aprendizagem longe do olhar do professor. Na verdade, este distanciamento pode contribuir para o desenvolvimento de algo que é fundamental na formação universitária: a autonomia intelectual.

Além disto, os cursos universitários a distância apresentam uma característica que pode se constituir numa vantagem frente aos cursos presenciais: o uso intenso da linguagem escrita. Nos cursos EAD a comunicação entre professor e aluno se dá basicamente através de textos, ao contrário do que ocorre no ensino presencial, dominado pela oralidade. Visto que o desenvolvimento das capacidades relacionadas à linguagem escrita é fundamental para a formação acadêmica e profissional dos alunos, contribuir para isto é um objetivo básico do ensino acadêmico. Neste artigo iremos refletir sobre a experiência das disciplinas de "Filosofia da educação" e "Seminário Integrador" (esta última ministrada ao longo de toda a duração do PEAD), tendo como foco o desenvolvimento do pensamento crítico.

"Pensamento crítico" é um conceito com muitas definições. Nas teorias educacionais, a acepção mais comum deste conceito é aquela oferecida por Mclaren: "pensamento crítico refere-se (...) à capacidade de reconhecer e derrotar a injustiça social" (DAM e VOLMAN, 2004, p. 362). Esta é uma definição substantiva do conceito que já pressupõe a descoberta da "injustiça social" e a avaliação de sua incorreção moral (outro conceito com muitas acepções). Numa concepção mais geral, o pensamento crítico é o desenvolvimento das capacidades cognitivas que nos permitem identificar e avaliar o que quer que seja, incluindo aí situações sociais. Ennis define o conceito como o "pensamento reflexivo que é focalizado em decidir o que crer ou fazer" (ENNIS, 1991, p. 474). Este pensamento reflexivo inclui necessariamente a arte de argumentar:

As habilidades envolvidas no pensamento crítico são as capacidades intelectuais necessárias para determinar se uma afirmação é racionalmente justificada - se há base suficiente para acreditar que a afirmação é verdadeira. Visto que qualquer tentativa racional para justificar uma afirmação pode ser entendida como um argumento, as habilidades envolvidas no pensamento crítico podem ser identificadas como as que incluem qualquer capacidade requerida para reconhecer, analisar e avaliar argumentos. (SCHLECHT, p. 132, 1989 )

Segundo Weston, "argumentar significa oferecer um conjunto de razões ou provas para suportar uma conclusão" (WESTON, 2000, p. xi), assim um argumento é uma estrutura de justificação composta de dois elementos básicos: o que se quer provar (a tese, a conclusão); e o que é utilizado para isto (as razões, as premissas). É importante ressaltar que há uma ligação entre as duas partes, embora esta relação nem sempre seja a implicação lógica restrita, pois nem todo argumento é uma dedução.

A dedução(1) é o paraíso dos lógicos, nela é possível avaliar o argumento exclusivamente através da análise de sua forma, evitando, assim, a imprecisão das 
palavras. Com a incorporação da matemática na análise formal dos argumentos, a lógica moderna ganha profundidade e precisão na análise, tornando-a muito atraente para o ensino da argumentação. Convém notar, contudo, que mesmo no ensino de lógica formal se requer uma introdução à análise do argumento em linguagem natural a fim de que o aluno perceba a relação entre o raciocínio formal e aquele que realiza em seu cotidiano. Indo mais além, percebemos que os argumentos do dia-a-dia raramente têm uma estrutura lógica "tão complexa que a análise de sua validade ou falta desta não pode ser revelada à intuição através da sua expressão num português claro" (BOWELL e KEMP, 2005, p. vii). Portanto, uma vez que o objetivo principal do desenvolvimento do pensamento crítico é desenvolver a capacidade de interpretar e produzir textos argumentativos em linguagem natural, é mais adequado utilizar as ferramentas cognitivas da lógica informal.

A lógica informal tem por escopo analisar e avaliar argumentos utilizando apenas a linguagem natural. Mas isto cria um problema com respeito à dedução, pois é raro encontrar argumentos deste tipo na linguagem cotidiana. É claro que sempre podemos transformar qualquer argumento num dedutivo simplesmente adicionando premissas, mas este procedimento "em nada ajuda quando cuidamos de avaliar um argumento porque ainda se fará necessário decidir se a premissa adicional é ou não verdadeira" (FISHER, 258).

É preciso perder o paraíso para se conquistar o uso cotidiano da argumentação, o que gera o problema da avaliação de argumentos não-dedutivos. Inbar apresenta quatro propostas de análises de argumentos não-dedutivos presentes na literatura contemporânea:

(1) [A análise da] argumentação refere-se às regras que se aplicam ao argumento a ser analisado. (2) O juízo humano desempenha um papel fundamental na crítica aos argumentos. (3) $\mathrm{O}$ aspecto essencial dos argumentos reside na sua dimensão semântica mais do que na formal. (4) A análise crítica dos argumentos é facilitada quando os relacionamos heuristicamente com os condicionais (INBAR, 1999, p. 27-8).

Destas quatro propostas de análise, gostaríamos de ressaltar a primeira e a terceira. Uma vez que argumentos não-dedutivos não são avaliados em termos da sua validade formal, então é necessário levar em conta a sua semântica. Por outro lado, existem regras que podem ser aplicadas para qualificar um argumento como aceitável, sólido ou persuasivo. Por exemplo, se alguém afirma que todos os políticos são corruptos em função do que vê na imprensa, podemos afirmar com razão que comete a falácia da generalização apressada. Não temos espaço aqui para analisar quais são as regras que coordenam os argumentos não-dedutivos, mas de forma geral elas têm um caráter negativo: indicam os erros (falácias) que tornam o argumento inconsistente.

Além disso, o ensino da lógica informal permite ao aluno compreender tudo o que está em jogo quando analisa aquilo que dá sustentação a uma tese: os pressupostos (entimemas), a natureza das razões (se são dados empírico ou definições, ou verdades de razão, etc.), e a forma como as razões foram obtidas. Tudo isto enriquece o modo como o aluno pode avaliar os argumentos que constituem as teorias científicas.

\section{Ensinando filosofia através da EAD}

A disciplina de Filosofia da Educação tinha como objetivo permitir aos alunos refletir sobre os aspectos éticos do ensino. Para tanto, iniciou-se com uma atividade 
simples de identificação de argumentos em parágrafos curtos; a seguir foi feito um debate entre os alunos, atividade esta que será objeto de nossa análise.

O debate teve como tema o "dilema do antropólogo francês": um antropólogo fictício que tem como princípio moral não interferir na cultura dos povos que estuda, pois julga que não existem quesitos transculturais que permitam avaliar qualquer cultura, chega numa ilha cujos nativos têm a estranha crença de que os homens brancos são mensageiros dos deuses e que, portanto, devem ser obedecidos. O antropólogo, então, é questionado pelos nativos com relação à verdade desta crença e diz, sabendo que é uma mentira, que a crença é verdadeira. O texto que descreve o dilema deixa claro que o antropólogo, ao mentir, sabia que estava deixando os nativos vulneráveis aos outros homens brancos que fatalmente iriam descobrir a ilha.

Assim descrita a situação, os alunos foram divididos em pequenos grupos nos fóruns do ROODA. A metade destes grupos deveria defender a decisão do antropólogo e a outra metade, contestá-la. O grupo que tinha por missão defender a decisão deveria debater para achar o melhor argumento e, feito isto, enviá-lo ao grupo que deveria contestá-la; este, por sua vez, faria o mesmo, apenas com a intenção oposta.

Feita esta primeira etapa, o grupo deve tentar refutar o argumento enviado pelo outro grupo. Na última etapa da atividade, os grupos devem debater qual é a melhor decisão a ser tomada. Cada etapa durou uma semana.

Vamos analisar o debate num grupo de oito alunas do pólo onde atuamos, que tinha por tarefa defender a decisão do antropólogo. Neste grupo ocorreram 59 intervenções em três semanas, destas vamos selecionar apenas 6 para ilustrar como a discussão foi conduzida.

A aluna "M" escreveu:

(2009-03-30; 20:12:36) :) Gurias, além do que disse a (...), também pode ser: * O antropólogo mente, porque se não o fizesse poderia ser morto pelos nativos. * Como o antropólogo considera que toda avaliação está condicionada pela cultura do avaliador, pode ter mentido pelo fato de que "mentir" faz parte da sua cultura. Que tal?

Então o professor interveio formalizando os argumentos das alunas e alertando para os passos que não estão claros:

(2009-04-04; 15:01:33 Tenho dúvidas: 1) "mentir" faz parte de qual cultura? 2) Se faz parte da cultura do antropólogo, então ele pode mentir?

Note-se que o professor não está emitindo o seu juízo sobre a decisão do antropólogo, mas apenas mostra às alunas os pontos fracos de seus argumentos. A aluna "M" utiliza como premissa uma condicional implícita: "Se mentir faz parte da cultura do antropólogo, então ele pode mentir". O professor questiona este argumento em dois níveis: a) ele depende de um fato: mentir é um costume na cultura do antropólogo? $\mathrm{O}$ argumento da aluna não apresenta este fato. b) Mesmo que seja um fato na cultura do antropólogo o hábito da mentira, ainda assim é correto mentir? Aqui o professor está sugerindo a distinção entre fatos e normas. 
Continuando o debate, a aluna "R", relatora do grupo que deveria atacar a decisão do antropólogo, postou o argumento do seu grupo:

(2009-04-06; 12:41:02) Somos o grupo 6 e coube a nós refutar, e esses são nossos 3 argumentos: 1- Claude deixa a cultura dos nativos frágil perante os próximos homens brancos no momento que "mente", confirmando a crença dos nativos quando foi questionado, provocando uma grande vulnerabilidade para os nativos, porque com a resposta dada por Claude, facilmente esse grupo poderá ser manipulado pelos brancos que passarem pela ilha, inclusive para explorar suas riquezas. 2- Equivoca-se o antropólogo quando nega que existam quesitos transculturais que nos permitem avaliar toda e qualquer cultura. A interferência do antropólogo não acontece só pela sua fala, pelas suas mentiras ou verdades. O seu modo de vestir, agir, ser, exerce uma influência visível para todos os nativos. O simples fato de ter chegado à ilha e como chegou e o que foi fazer já é uma interferência, na cultura que ali se estabeleceu. 3- A falta de argumentos e de preparação para trabalhar com os questionamentos é um ponto negativo porque Claude pensou que não seria abordado por isso não soube como lidar com a situação. Claude poderia ter explicado aos nativos que alguns brancos podem ser mensageiros dos deuses, assim como em todos os grupos sociais há um líder, mas, que ele não era um mensageiro, que estava em busca de outros conhecimentos. Com a pergunta dos nativos, ele teria chance de explicar a cultura do homem branco, não os deixando com a antiga crença.

O grupo que estamos analisando tinha a tarefa de refutar este argumento. Apresentaremos o argumento da aluna "E":

(2009-04-06; 23:00:23) O que vocês acham destas justificativas para defesa do antropólogo: 1)Se o antropólogo revelasse a verdade,talvez não fosse aceito pelo grupo,e no momento,ele precisava que o aceitassem. 2)Se o princípio do pesquisador era não julgar o modo de vida dos nativos então se justifica o fato de ele aceitar e concordar que era um mensageiro dos deuses. 3)A missão do antropólogo é estudar os nativos ele realmente não pode interferir em nada, principalmente em suas crenças. Esta foi uma decisão tomada por ele, pois ele esta lá como observador e não para mudar a história da vida daqueles habitantes.

O que gerou a seguinte intervenção do professor:

(2009-04-08; 11:16:03) Oi E, mas o grupo oposto enviou para vocês um argumento que põe em dúvida o princípio que o antropólogo segue, que tal tentar refutar este argumento: "2- Equivoca-se o antropólogo Frances Claude Lee, quando nega que existam quesitos transculturais que nos permitem avaliar toda e qualquer cultura.”A interferência do antropólogo não acontece só pela sua fala, pelas suas mentiras ou verdades. O seu modo de vestir, agir, ser, exerce uma influência visível para todos os nativos. O simples fato de ter chegado à ilha e como chegou e o que foi fazer já é uma interferência, na cultura que ali se estabeleceu." 
O professor está aqui atentando a aluna para o fato dela não ter respondido ao argumento mais forte do outro grupo, a saber, o "2", aquele que questiona o princípio que guia a decisão do antropólogo. Apenas uma aluna do grupo percebeu esta dificuldade:

(2009-04-11; 23:31:40) Estou achando muito difícil refutar o $2^{\circ}$ argumento do grupo 6, uma vez que até concordo com ele... Mas o francês, quando concorda ser um mensageiro dos deuses, não interfere na cultura dos nativos no quesito "suas crenças" naquele momento, mesmo que futuramente isso os prejudique. Assim, interfere o menos possível, se de fato sua presença já interfere.

Note-se que a aluna não refuta a primeira parte do argumento "2" do outro grupo, apenas a segunda parte: "O seu modo de vestir, agir, ser, exerce uma influência visível para todos os nativos. $\mathrm{O}$ simples fato de ter chegado à ilha e como chegou e o que foi fazer já é uma interferência, na cultura que ali se estabeleceu". Ou seja, apenas a parte do argumento que afirma que a mera presença do antropólogo já viola o seu princípio de não-intervenção nas outras culturas. Esse é o momento do professor mostrar aos alunos que ao avaliarmos um argumento devemos levar em conta as premissas mais fortes, pois só deste modo se pode atingir a verdade, ainda que contingente, sobre um tópico de debate. Mas nenhuma aluna do grupo elaborou uma réplica a esta premissa, então o professor tomou como seu encargo realizar esta tarefa, enviando perguntas para o grupo que elaborou o argumento:

(2009-04-06; 02:15:15) Creio que a $\mathrm{N}$ tenha um argumento forte: "Equivoca-se o antropólogo quando nega que existam quesitos transculturais que nos permitem avaliar toda e qualquer cultura.” Mas é importante tornar mais claro este argumento e, para ajudá-las, ofereço duas perguntas: 1. Quais seriam os princípios transculturais envolvidos na decisão do antropólogo? 2. Por que estes princípios são transculturais?

Existem obviamente limites neste processo de desenvolvimento da arte de argumentar. O tempo é um fator limitante: somente através de várias atividades de análise e produção de argumentos torna-se possível dominar esta capacidade. Isso explica o fato de que o grupo que elaborou o argumento não conseguir defendê-lo: as perguntas acima ficaram sem resposta. Mesmo assim, a atividade proporcionou às alunas um aumento na reflexão sobre o tema da moralidade, como atesta o depoimento de uma aluna no mencionado fórum:

(2009-04-19; 12:33:40) Passamos por um processo de questionamento sobre nossas "verdades" e de reflexão sobre a forma de agir e reagir do ser humano. Acabamos por nos questionar mais sobre a mentira que o antropólogo usou do que sobre as diferenças culturais que possam existir entre diferentes civilizações. E aí nos deparamos com o que considero ser o maior dilema, a verdade é um princípio moral universal, tão antigo que faz parte dos "Dez Mandamentos" cristãos, mas todos sabem que existem 
momentos e situações na vida do ser humano em que mentimos ou omitimos verdades. E aí, como devemos encarar isso? Devemos ser rígidos e punitivos ou devemos levar em conta a natureza da situação que tornou a mentira necessária? E desta forma acredito que caímos numa reflexão ainda mais profunda: qual é o papel do juízo moral e a importância dos valores morais na convivência humana?

\section{Seminário Integrador}

A disciplina "Seminário Integrador" teve como função principal auxiliar os alunos nas aprendizagens ocorridas ao longo de todo PEAD. Dentre as várias atividades realizadas ao longo dos nove semestres de funcionamento da disciplina, vamos analisar a que durou mais tempo: o blog dos portfólios de aprendizagem.

O portfólio de aprendizagem "é uma produção intelectual, relativamente curta, que mostra, de forma sucinta e substantiva, o professor como sujeito reflexivo e construtor da sua experiência pedagógica" (CARVALHO e PORTO, 2005, p.13.). O portfólio de aprendizagem foi utilizado no Seminário Integrador como uma ferramenta de auto-avaliação continuada, através da criação de num blog individual onde cada aluna e aluno postariam semanalmente comentários sobre as aprendizagens ocorridas nas disciplinas do curso. Não era intenção dos professores da disciplina, contudo, que o portfólio se transformasse num "mea-culpa" ou no auto-elogio, tampouco era nosso objetivo que fosse apenas um mero relato das aulas.

Visando transformá-lo numa genuína reflexão sobre as aprendizagens realizadas, instruímos os alunos-docentes a postarem provas das aprendizagens realizadas, o que poderia ser feito por meio de "links" para as atividades feitas nas disciplinas, ou a descrição das atividades relacionadas com o curso que realizaram com seus alunos nas escolas. Mas estas provas deveriam vir inseridas num contexto argumentativo onde seria justificada a escolha de uma determinada atividade como prova de aprendizagem.

A argumentação, portanto, é uma estratégia básica na confecção dos portfólios de aprendizagem. Ela também é uma das capacidades básicas do pensamento crítico, pois o argumento é a forma básica de se tentar provar uma afirmação, tese, teoria ou opinião.

Ao coordenarmos a atividade do blog do portfólio de aprendizagens percebemos a dificuldade da auto-avaliação reflexiva, pois a maior parte das postagens continha apenas relatos das aprendizagens com eventuais observações sobre a influência destas na vida docente da aluna. A fim de desenvolvermos nas alunas a capacidade da autoavaliação reflexiva propusemos a seguinte estrutura básica argumentativa:

Razão 1: a descrição da atividade de aprendizagem;

Razão 2: algum critério de avaliação de aprendizagem;

Conclusão: ocorreu a aprendizagem.

As alunas não conseguiriam realizar todo este processo em razão da dificuldade de se estabelecer critérios de auto-avaliação, mas conseguiriam elaborar argumentos simples com a descrição da aprendizagem, como é ilustrado pelo exemplo a seguir extraído do blog do portfólio de aprendizagens da aluna R.: 
Na interdisciplina do Seminário Integrador realizei as leituras dos textos referentes às perguntas feitas pelos alunos e nosso papel como educadoras diante dos questionamentos.

Através do texto "Qual é a questão”, de Beatriz Magdalena e Íris Costa, aprendi que as questões dos alunos geram projetos de aprendizagem e interdisciplinaridade. "Os alunos podem expressar-se através de novas formas, perguntar e buscar respostas originais, tanto individual como coletivamente. Isto fica evidente nos exemplos de questões, geradoras de projetos de aprendizagem". Pág 3 "Estas questões, que provavelmente não seriam as que o professor faria aos seus alunos como convite a estudar, abrem janelas inusitadas para que o conhecimento de construa interdisciplinarmente".

Uma evidência de aprendizagem é que estou trabalhando um projeto de Estudos Sociais sobre escola. Havia planejado várias atividades para que as crianças relembrassem o nome da escola, descobrissem sua importância, onde fica situada (endereço), função exercida por cada funcionário, localização dos setores, no entanto surgiu uma questão de alguns alunos: "Por que nossa escola se chama 'EF'?”Através desta questão realizamos uma pesquisa sobre a história desta pessoa chamada "EF" e assim aprofundamos nossos conhecimentos sobre a escola. As crianças se sentiram motivadas em pesquisar, as descobertas geraram satisfação. Desta forma trabalhamos temas do interesse das crianças promovendo uma aprendizagem ativa e significativa.

Analisando o texto percebemos que apresenta a seguinte estrutura:

1. Proposição que descreve o conteúdo da lição de uma disciplina: "Através do texto 'Qual é a questão', de Beatriz Magdalena e Íris Costa, aprendi que as questões dos alunos geram projetos de aprendizagem e interdisciplinaridade".

2. Proposição que descreve a aprendizagem realizada: "Uma evidência de aprendizagem é que estou trabalhando um projeto de Estudos Sociais sobre escola".

3. Conclusão implícita: ocorreu uma aprendizagem.

Como dissemos mais acima, as alunas tiveram dificuldade em explicitar o critério que identifica a realização de uma aprendizagem, deixando-o implícito no argumento. No caso acima, o critério é simples: quando o aluno realiza a atividade proposta pelos professores, ocorre aprendizagem. Demasiado simples, mas como a aluna não o percebe claramente, não percebe também suas limitações.

Desenvolver nos alunos a capacidade de explicitar as razões de suas asserções possibilita a auto-avaliação efetiva de suas concepções, o que é um passo necessário no desenvolvimento do pensamento crítico.

A atividade do blog do portfólio de aprendizagens, embora não tenha atingido todos os seus objetivos, conduziu as alunas a um nível mais elevado de reflexão sobre o seu processo de aprendizagem.

\section{Considerações finais}


O desenvolvimento da capacidade de argumentar é um momento necessário no desenvolvimento da capacidade crítica do aluno. Uma forma de desenvolver esta capacidade é através de atividades onde o aluno tenha que expressar sua opinião de modo argumentado. Este processo pode ser realizado também no modo EAD, desde que haja uma efetiva interação entre os alunos e os professores e tutores, com o cuidado de conduzir os alunos na produção do argumento, ao invés de simplesmente indicar qual a seria a solução mais correta para o problema.

\section{Notas:}

Estamos usando "dedução" na acepção corriqueira dos livros de lógica, a saber, aquele argumento onde afirmar as premissas e negar a conclusão implica contradição. Toulmin nos lembra, entretanto, que esta não é a acepção corriqueira do termo, pois usualmente tomamos "dedução" como significando qualquer tipo de inferência. É neste sentido que Sherlock Holmes faz "deduções", quando, no sentido lógico, realiza raciocínios indutivos (TOULMIN. p. 112-3)

\section{Referências bibliográficas:}

BOWELL, Tracy; KEMP, Gary. Critical thinking: a concise guide. Nova Iorque: Routledge, 2005.

DAM, Geert ten ; VOLMAN, Monique. "Critical thinking as a citizenship competence: teaching strategies". Learning and Instruction, N N 14 p. 359-379, 2004.

ENNIS, Catherine D. "Discrete Thinking Skills in Two Teachers' Physical Education Classes". The Elementary School Journal, V. 91, № 5, p. 473-487 1991.

FISHER, Alec. A Lógica dos Verdadeiros Argumentos. São Paulo : Novo Conceito, 2008.

INBAR, Michael. "Argumentation as Rule-Justified Claims: Elements of a Conceptual Framework for the Critical Analysis of Argument". Argumentation

$\mathrm{N}^{\mathrm{o}}$ 13, p. 27-42, 1999.

PORTO, Leonardo. S. ; CARVALHO, Marie Jane. S. Portfólio Educacional. 1. ed. Porto Alegre: Editora da UFRGS, 2005.

SCHLECHT, Ludwig F. "Critical Thinking Courses: Their Value and Limits". Teaching Philosophy, V 12, № 2, 131- 140, 1989.

TOULMIN, Stephen E. The Uses of Argument. Nova Iorque: Cambridge University Press, 2003.

WESTON, Anthony. A Rulebook for Arguments. Indianapolis: Hackett, 2000. 
